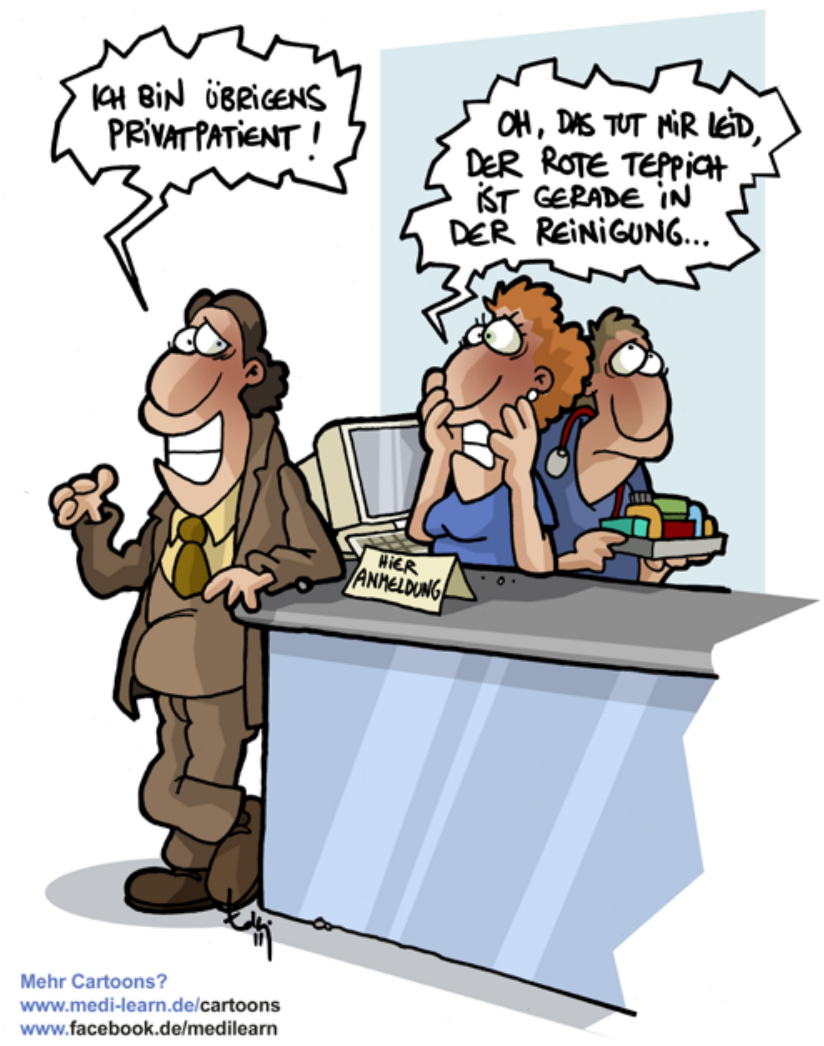

„Dann würd' ich mich wahrscheinlich für Bayern München entscheiden."

Bundesfinanzminister Wolfgang Schäuble (CDU) auf die Frage, was er machen würde, wenn er wählen könnte zwischen dem Amt des Bundeskanzlers, des Bundespräsidenten oder des Präsidenten des FC Bayern München.

\title{
Angebohrt
}

\section{Fee mit Million}

Geld allein macht nicht glücklich. Ist klar. Da gibt es noch ganz viele andere Dinge, die wichtiger sind im Leben - Gesundheit, Familie, Freunde, Spaß und so. Das sagen ja alle. Und gleichzeitig gibt es dann solche Zahlen aus Studien, die durchaus alarmierend deutlich machen: Geld ist für die Deutschen offenbar doch ein enormer Glücksfaktor. Wie sonst lässt es sich erklären, dass zwei Drittel der Deutschen glücklicher wären, wenn sie das Doppelte ihres aktuellen Gehaltes verdienten?

Wer Geld und Glück nicht so recht zusammenbringen möchte, dem sei das aktuell erschienene Buch „Wir Deutschen und das Geld“ empfohlen, in dem der Zusammenhang auf Dutzenden Grafiken und Statistiken augenfällig wird. Was Geld angeht, sind die Deutschen offenbar hellwach. Von wegen verschlafener Deutscher Michel. Sparfüchse vor! Denn im Hamstern, Horten, Anlegen und Vermehren ist Deutschland einfach unschlagbar. Nur Bares ist Wahres. Für mehr Geld ist vielen offenbar auch kaum ein Opfer zu groß: Wenn die gute Fee mit einer Million Euro vorbeikäme und eine Gegenleistung für die Kohle erwarten würde, dann würden fast 40 Prozent der Deutschen ein Jahr lang auf Sex verzichten - und 27 Prozent sogar auf ihren Führerschein. Ist halt so eine Sache mit der Glücksdefinition.

\section{Fee in Feinripp}

Was ist rosarot und trägt ein Glitzerkrönchen? Prinzessin Lillifee? Ja, die auch. Doch zurzeit macht weniger das Zeichentrickpinzessinnentopmodel mit seinem rosa Fummel Furore als ein Schweizer Zahnarzt, der mit seinem rosafarbenen Tülltutu, Flügelchen, Zauberstab und Krone als Zahnfee durchs Internet turnt - und nicht nur da. Offenbar ist der Zahnfee-Zahnarzt auch ganz leibhaftig auf Werbetour für seine neue Praxis und erfreut Passanten im Einkaufscenter. Allein die Springerstiefel und das Feinrippachselhemd stören - gewollt und augenzwinkernd - ein wenig den Gesamteindruck. „Ja, er ist es wirklich“ steht auf der Facebook-Seite von Daniel Winter. Zur Behandlung tritt der Mann dann vermutlich ohne Zauberstab und Tutu auf, was allerdings zu einiger Enttäuschung bei seiner Fanschar (im Alter von vier bis acht oder ab 50) führen dürfte. Immerhin, der Herr Fee ist ein Hingucker. Das muss man erstmal schaffen. Eine gelungene Kampagne. Da könnte sich Apple mal eine Scheibe abschneiden. Denn der Computergigant kann sich seit der Vorstellung des neuen iPhones vor Spott kaum noch retten. Kabellose Kopfhörer sollten ja der Superrenner sein. Und was kommt dabei raus? Im Netz wird Apple veräppelt: Die dollen Kopfhörer sähen aus wie die Aufsätze von Elektrozahnbürsten. Da muss wohl die Zahnfee mal zur Nachhilfe kommen. sas 